\title{
Application of the Social Inquiry Learning Model to Improve Social Studies Learning
}

\author{
Novita Donna Zamzami \\ Universitas Sebelas Maret \\ novitadonnazamzami@gmail.com
}

\section{Article History}

received 30/4/2021

\author{
revised 30/5/2021 accepted 30/6/2021
}

\begin{abstract}
The social studies learning process demands the ability of teachers to develop learning models that can encourage students to think critically. Inquiry is a learning activity that emphasizes critical thinking processes to find answers to the problems in question. This study aims to describe the steps for applying the social inquiry learning model to improve social studies learning. This research is a Classroom Action Research. The data used are quantitative data and qualitative data. Quantitative data in the form of student learning outcomes, and qualitative data in the form of information on the social studies learning process by applying the model. Data collection techniques using observation, interviews, and tests. The results showed that the application of the social inquiry learning model carried out 8 steps, namely: (1) orientation, (2) formulating problems, (3) formulating hypotheses, (4) defining hypotheses, (5) exploring hypotheses, (6) collecting data, (7) prove the hypothesis and (8) the conclusion can improve social studies learning as indicated by an increase in the percentage of students' completeness by $71.42 \%$ in the first cycle, $78.57 \%$ in the second cycle, and $85.71 \%$ in the third cycle.
\end{abstract}

Keywords: Critical Thinking, Social Inquiry, Social Studies Learning

\begin{abstract}
Abstrak
Proses pembelajaran IPS menuntut kemampuan guru dalam mengembangkan model pembelajaran yang dapat mendorong siswa untuk berfikir kritis. Inkuiri adalah kegiatan pembelajaran yang menekankan pada proses berfikir kritis untuk menemukan jawaban dari masalah yang dipertanyaan. Penelitian ini bertujuan untuk mendeskripsikan langkah-langkah penerapan model pembelajaran social inquiry untuk meningkatkan pembelajaran IPS. Penelitian ini merupakan Penelitian Tindakan Kelas. Data yang digunakan adalah data kuantitatif dan data kualitatif. Data kuantitatif berupa hasil belajar siswa, dan data kualitatif berupa informasi proses pembelajaran IPS dengan menerapkan model. Teknik pengumpulan data menggunakan observasi, wawancara, dan tes. Hasil penelitian menunjukkan bahwa penerapan model pembelajaran social inquiry dilaksanakan 8 langkah yaitu: (1) orientasi, (2) merumuskan masalah, (3) menyusun hipotesis, (4) mendefinisikan hipotesis, (5) eksplorasi hipotesis, (6) mengumpulkan data, (7) membuktikan hipotesis dan (8) kesimpulan dapat meningkatkan pembelajaran IPS yang ditunjukan dengan peningkatan persentase ketuntasan siswa sebesar $71,42 \%$ pada siklus I, $78,57 \%$ pada siklus II, dan $85,71 \%$ pada siklus III.

Kata kunci: Berfikir Kritis, Social Inquiry, Pembelajaran IPS
\end{abstract}




\section{PENDAHULUAN}

Pada pembukaan UUD tertulis jelas bahwa salah satu tujuan nasional adalah mencerdaskan kehidupan bangsa. Salah satu cara untuk mencerdaskan Bangsa Indonesia yaitu melalui pendidikan. Pendidikan merupakan hal terpenting dalam perkembangan peradaban dunia. Hal ini karena pendidikan mampu membawa kehidupan manusia ke arah yang lebih baik. Pendidikan adalah usaha sadar untuk mengembangkan potensi peserta didik agar memiliki keimanan terdahap Tuhan, kecerdasan, akhlak mulia dan keterampilan dalam kehidupan bermasyarakat, berbangsa dan bernegara (UU Nomor 20 Tahun 2003).

Potensi yang dimiliki peserta didik harus dikembangkan sehingga tujuan nasional dapat terwujud. Sekolah merupakan tempat yang mampu mengembangkan potensi peserta didik. Sekolah memberikan pengalaman belajar bagi peserta didik. Dibangku sekolah, peserta didik dibekali nilai kepribadian, pengetahuan, dan keterampilan dasar yang cukup untuk mempersiapkan diri ke jenjang yang lebih tinggi dan agar mampu terjun di masyarakat. Ada beberapa mata pelajaran yang diajarkan pada jenjang sekolah dasar, salah satunya ilmu pengetahuan sosial.

IImu Pengetahuan Sosial (IPS) merupakan salah satu mata pelajaran yang penting untuk dipelajarai pada peserta didik di sekolah dasar. Melalui pembelajaran IPS ini peserta didik SD diharapkan dapat mengembangkan aspek nilai-sikap, aspek pengetahuan, dan aspek keterampilan sosial (Susanto, 2014: 36). Sapriya (2014: 201) menyatakan bahwa mata pelajaran IPS bertujuan agar peserta didik memiliki kemampuan sebagai berikut: (1) memahami konsep yang berkaitan dengan kehidupan masyarakat dan lingkungannya, (2) memiliki kemampuan untuk berfikir logis dan kritis, rasa ingin tahu, inkuiri, memecahkan masalah, dan keterampilan dalam kehidupan sosial, (3) memiliki komitmen dan kesadaran dalam nilai sosial dan kemanusiaan, (4) memiliki kemampuan berkomunikasi, bekerja sama, dan (5) berkompetisi dalam masyaakat yang majemuk.

Berdasarkan tujuan pembelajaran IPS di atas, bahwa pembelajaran IPS menuntut peserta didik mampu berfikir secara inkuiri. Inkuiri adalah kegiatan pembelajaran yang menekankan pada proses berfikir kritis dan analitis untuk mencari dan menemukan sendiri jawaban dari masalah yang sedang dipertanyaan (Sanjaya, 2013: 196). Proses pembelajaran IPS menuntut kemampuan guru dalam mengembangkan model pembelajaran yang dapat menunjang dan mendorong peserta didik untuk berfikir logis, sistematis dan kritis. Guru hendaknya mampu memberikan kemudahan kepada peserta didik sehingga peserta didik dapat menghubungkan antara pengetahuan yang dimilikinya dengan penerapan kehidupan nyata dalam masyarakat. Dalam mewujudkan hal tersebut dibutuhkan peranan dari guru atau tenaga pendidik. Guru harus mampu menerapkan model pembelajaran yang dapat meningkatkan kemampuan sosial peserta didik.

Berdasarkan hasil observasi pada pembelajaran IPS kelas V di SDN 1 Jatisari Kecamatan Kebumen Kabupaten Kebumen pada tanggal 10 November 2020 menunjukkan bahwa pembelajaran IPS peserta didik kelas V pada Tema 9 Bendabenda di Sekitar masih belum menunjukkan hasil yang maksimal. Hal ini dapat diamati ketika pembelajaran di kelas sedang berlangsung yaitu: (1) sebanyak 14 peserta didik belum mencapai $\mathrm{KKM}=85$, (2) guru lebih sering menggunakan ceramah pada mata pelajaran IPS, (3) peserta didik tidak dilibatkan secara aktif dalam pembelajaran, (4) peserta didik terlihat kurang tertarik dengan pembelajaran IPS yang sedang berlangsung dan (5) peserta didik tidak diminta mencari sendiri jawaban atas permasalahan yang dihadapi.

Berdasarkan fakta tersebut guru masih menggunakan model pembelajaran konvensional dalam pembelajaran IPS. Pelaksanaan pembelajaran IPS di SD masih berpusat pada guru (teacher centered). Peran guru yang masih dominan dalam proses pembelajaran menyebabkan lemahnya proses dan peserta didik menjadi pasif. 
Pembelajaran yang baik seharusnya terpusat pada peserta didik (student centered). Peserta didik seharusnya dilibatkan secara aktif dalam pembelajaran, termasuk dalam menentukan masalah, menyusun hipotesis, mengumpulkan data, menguji hipotesis dan akhirnya peserta didik dapat menarik kesimpulan dari pembelajaran yang dilakukan. Pada model pembelajaran inkuiri, peserta didik mampu menyelidiki dan menemukan ide-ide sehingga mampu melakukan perspektif pada masa yang akan datang.

Berdasarkan hasil observasi yang telah dilakukan peneliti akan menerapkan model pembelajaran social inquiry. Hal ini karena model pembelajaran social inquiry dapat meningkatkan pembelajaran IPS, sesuai dengan penelitian yang dilakukan oleh Salam (2017: 2-5), bahwa penerapan model social inquiry dapat meningkatnya pembelajaran IPS dan hasil belajar peserta didik. Selain itu model pembelajaran inkuiri sosial ini sebagai suatu rangkaian kegiatan belajar yang melibatkan secara maksimal seluruh kemampuan peserta didik untuk mencari dan menyelidiki secara sistematis, kritis, dan analitis (Widiantara dkk, 2013: 4). Anam (2016: 16) menyebutkan bahwa salah satu kelebihan model social inquiry yaitu mampu menciptakan situasi belajar mengajar yang lebih merangsang. Oleh karena itu peneliti menerapkan model pembelajaran social inquiry. Diharapkan dengan menerapkan model pembelajaran social inquiry pembelajaran IPS dapat meningkat.

Berdasarkan uraian di atas, peneliti tertarik untuk melaksanakan penelitian tindakan kelas dengan judul "Penerapan Model Pembelajaran Social Inquiry untuk Meningkatkan Pembelajaran IPS tentang Kegiatan Usaha Ekonomi pada Peserta didik Kelas V SD Negeri 1 Jatisari Tahun Ajaran 2020/2021, maka dapat dirumuskan masalah yang muncul yaitu: (1) bagaimakah langkah-langkah penerapan model pembelajaran social inquiry? dan (2) apakah penerapan model pembelajaran social inquiry dapat meningkatkan pembelajaran IPS pada siswa kelas V SD Negeri 1 Jatisari tahun ajaran 2020/2021? Penelitian ini bertujuan untuk: (1) mendeskripsikan langkahlangkah penerapan model pembelajaran social inquiry dan (2) meningkatkan pembelajaran IPS melalui penerapan model pembelajaran social inquiry pada siswa kelas V SD Negeri 1 Jatisari tahun ajaran 2020/2021.

\section{METODE}

Penelitian ini merupakan penelitian tindakan kelas (PTK) yang dilaksanakan dalam tiga siklus. Penelitian ini menggunakan prosedur penelitian modifikasi dari Arikunto, Suhardjono \& Supardi (2014: 16) yang setiap siklusnya terdiri dari tahap perencanaan, pelaksanaan, pengamatan, dan refleksi.Setiap siklus terdiri dari empat tahap yaitu: perencanaan, pelaksanaan, pengamatan, dan refleksi. Subjek dalam penelitian ini adalah siswa kelas V SD Negeri 1 Jatisari yang berjumlah 14 siswa. Data yang digunakan adalah data kuantitatif berupa nilai evaluasi keterampilan membaca intensif dan data kualitatif berupa hasil observasi dan wawancara. Teknik pengumpulan data menggunakan observasi, wawancara, tes, dan studi dokumen. Validitas data menggunakan triangulasi teknik dan sumber. Analisis data meliputi reduksi data, penyajian data, dan penarikan kesimpulan. Indikator kinerja penelitian ini adalah peningkatan pembelajaran IPS dengan target $85 \%$ dan ketuntasan minimal siswa dengan target $85 \%$.

\section{HASIL DAN PEMBAHASAN.}

Penelitian ini dilaksanakan selama tiga siklus dengan menerapkan langkah model social inquiry. Tahapan langkah pembelajaran social inquiry menurut The Ministry Education (2008: 9) yaitu: (1) focus on learning topic, pada tahap ini ditentukan topik yang akan dikaji (2) conceptual understanding, pada tahap ini siswa memberikan pemahaman konsep yang mereka miliki, (3) considering response and decision, pada 
tahap ini siswa memberikan tanggapannya (4) exploring value and perspective pada tahap ini siswa menggabungkan fakta temuan, (5) finding out information, pada tahap ini siswa mengumpukan data guna membuktikan hipotesis, (6) reflecting and evaluating. pada tahap ini siswa menyimpulkan dan membentuk solusi masalah.

Tujuh langkah model pembelajaran social inquiry yaitu: (1) orientasi, (2) merumuskan masalah, (3) menyusun hipotesis, (4) mendefinisikan hipotesis, (5) eksplorasi hipotesis, (6) mengumpulkan data, (7) membuktikan hipotesis dan (8) kesimpulan. Langkah-langkah tersbut sesuai seperti yang disampaikan Sutikno (2013: 83) dan The Ministry Education (2008: 9).

Dari pendapat diatas dapat diperoleh bahwa Langkah-langkah sosial inquiry memiliki 8 langkah yaitu: (1) orientasi, (2) merumuskan masalah, (3) menyusun hipotesis, (4) mendefinisikan hipotesis, (5) eksplorasi hipotesis, (6) mengumpulkan data, (7) membuktikan hipotesis dan (8) kesimpulan

Hasil pengamatan terhadap pelaksanaan pembelajaran bahasa Indonesia dengan menerapkan model pembelajaran social inquiry mengalami peningkatan pada setiap siklusnya yaitu:

Tabel 1. Tabel Hasil Pengamatan Penerapan Model Pembelajaran social inquiry

\begin{tabular}{cccc}
\hline Sumber Data & \multicolumn{3}{c}{ Siklus } \\
\hline & I & II & III \\
\hline Guru (\%) & 71,28 & 81,05 & 85,50 \\
\hline Siswa (\%) & 70,93 & 82,56 & 85,64 \\
\hline
\end{tabular}

Berdasarkan tabel 1 di atas, observasi terhadap guru pada siklus I persentase hasil $70,37 \%$ dan pada siklus II menjadi $82,97 \%$. Antara siklus I dan II meningkat 12,6\%. Pada siklus III meningkat 4,71\% menjadi 87,68\%. Observasi terhadap siswa pada siklus I persentase mencapai $70,65 \%$ dan pada siklus II menjadi $80,17 \%$. Antara siklus I dan II meningkat $9,52 \%$. Pada siklus III peningkatan terjadi $7,51 \%$ menjadi $87,68 \%$. Dapat disimpulkan bahwa setiap siklus mengalami peningkatan, berarti langkah social inquiry setiap siklus semakin meningkat.

Sementara data hasil belajar siswa diperoleh dari hasil evaluasi yang dilakukan pada akhir pembelajaran setiap pertemuan pada siklus I, II, dan III. Analisis perbandingan hasil belajar yang diperoleh siswa pada siklus I, II, dan III dimuat pada tabel berikut.

Tabel 2. Analisis Hasil Belajar Siswa Siklus I, II, dan III

\begin{tabular}{llll}
\hline & Siklus I (\%) & Siklus II (\%) & Siklus III (\%) \\
\hline Tuntas & 71,42 & 78,57 & 85,71 \\
Belum Tuntas & 28,58 & 21,43 & 14,29 \\
\hline
\end{tabular}

Berdasarkan tabel 2 di atas, dapat disimpulkan bahwa persentase ketuntasan siswa juga meningkat dari $71,42 \%$ di siklus I, menjadi $78,57 \%$ di siklus II, dan $85,71 \%$ di siklus III.

Penelitian ini dilaksanakan selama tiga siklus dengan menerapkan langkah model social inquiry. Tahapan langkah pembelajaran social inquiry menurut The Ministry Education (2008: 9) yaitu: (1) focus on learning topic, pada tahap ini ditentukan topik yang akan dikaji (2) conceptual understanding, pada tahap ini siswa memberikan pemahaman konsep yang mereka miliki, (3) considering response and decision, pada tahap ini siswa memberikan tanggapannya (4) exploring value and perspective pada tahap ini siswa menggabungkan fakta temuan, (5) finding out information, pada tahap 
ini siswa mengumpukan data guna membuktikan hipotesis, (6) reflecting and evaluating. pada tahap ini siswa menyimpulkan dan membentuk solusi masalah.

Tujuh langkah model pembelajaran social inquiry yaitu: (1) orientasi, (2) merumuskan masalah, (3) menyusun hipotesis, (4) mendefinisikan hipotesis, (5) eksplorasi hipotesis, (6) mengumpulkan data, (7) membuktikan hipotesis dan (8) kesimpulan. Langkah-langkah tersbut sesuai seperti yang disampaikan Sutikno (2013: 83) dan The Ministry Education (2008: 9).

Dari pendapat diatas dapat diperoleh bahwa Langkah-langkah sosial inquiry memiliki 8 langkah yaitu: (1) orientasi, (2) merumuskan masalah, (3) menyusun hipotesis, (4) mendefinisikan hipotesis, (5) eksplorasi hipotesis, (6) mengumpulkan data, (7) membuktikan hipotesis dan (8) kesimpulan

Hasil pengamatan terhadap pelaksanaan pembelajaran bahasa Indonesia dengan menerapkan model pembelajaran social inquiry mengalami peningkatan pada setiap siklusnya yaitu:

Tabel 1. Tabel Hasil Pengamatan Penerapan Model Pembelajaran social inquiry

\begin{tabular}{cccc}
\hline Sumber Data & \multicolumn{3}{c}{ Siklus } \\
\hline & I & II & III \\
\hline Guru (\%) & 71,28 & 81,05 & 85,50 \\
\hline Siswa (\%) & 70,93 & 82,56 & 85,64 \\
\hline
\end{tabular}

Berdasarkan tabel 1 di atas, observasi terhadap guru pada siklus I persentase hasil $70,37 \%$ dan pada siklus II menjadi $82,97 \%$. Antara siklus I dan II meningkat 12,6\%. Pada siklus III meningkat 4,71\% menjadi $87,68 \%$. Observasi terhadap siswa pada siklus I persentase mencapai $70,65 \%$ dan pada siklus II menjadi $80,17 \%$. Antara siklus I dan II meningkat 9,52\%. Pada siklus III peningkatan terjadi $7,51 \%$ menjadi $87,68 \%$. Dapat disimpulkan bahwa setiap siklus mengalami peningkatan, berarti langkah social inquiry setiap siklus semakin meningkat.

Sementara data hasil belajar siswa diperoleh dari hasil evaluasi yang dilakukan pada akhir pembelajaran setiap pertemuan pada siklus I, II, dan III. Analisis perbandingan hasil belajar yang diperoleh siswa pada siklus I, II, dan III dimuat pada tabel berikut.

Tabel 2. Analisis Hasil Belajar Siswa Siklus I, II, dan III

\begin{tabular}{llll}
\hline & Siklus I (\%) & Siklus II (\%) & Siklus III (\%) \\
\hline Tuntas & 71,42 & 78,57 & 85,71 \\
Belum Tuntas & 28,58 & 21,43 & 14,29 \\
\hline
\end{tabular}

Berdasarkan tabel 2 di atas, dapat disimpulkan bahwa persentase ketuntasan siswa juga meningkat dari $71,42 \%$ di siklus I, menjadi $78,57 \%$ di siklus II, dan $85,71 \%$ di siklus III.

\section{SIMPULAN}

Berdasarkan rumusan masalah, hasil penelitian, dan pembahasan dalam penelitian ini, dapat diambil kesimpulan sebagai berikut:

1. Model pembelajaran social inquiry dalam peningkatan pembelajaran IPS tentang kegiatan jual beli pada siswa kelas V SDN Jatisari tahun ajaran 2020/2021 dilaksanakan dengan langkah-langkah: (1) orientasi, (2) merumuskan masalah, (3) menyusun hipotesis, (4) mendefinisikan hipotesis, (5) eksplorasi hipotesis, (6) menumpulkan data, (7) membuktikan hipotesis, dan (8) kesimpulan. Berdasarkan penerapan model social inquiry pada observasi guru, masing-masing diperoleh 
siklus I mencapai $71,28 \%$, siklus II mencapai $81,05 \%$, dan pada siklus III mencapai $85,50 \%$.

2. Penerapan model pembelajaran social inquiry dapat meningkatkan pembelajaran IPS tentang kegiatan jual beli pada siswa kelas V SDN Jatisari tahun ajaran 2020/2021. Hal ini dibuktikan dengan hasil penerapan model pada observasi guru, masing-masing diperoleh siklus I mencapai 71,42\%, siklus II mencapai 78,57\%, dan pada siklus III mencapai $85,71 \%$. Hasil belajar siswa juga mengalami peningkatan yaitu rata-rata nilai keseluruhan siklus I sebesar 71,42 , siklus II sebesar 84,56, dan siklus III sebesar 87 .

\section{DAFTAR PUSTAKA}

Anam, K. (2016). Pembelajaran Berbasis Inkuiri Metode dan Aplikasi. Yogyakarta: Pustaka Penerbit.

Arikunto, S. (2013). Prosedur Penelitian. Jakarta: Rineka Cipta..

Salam, R. (2017). Model Pembelajaran Inkuiri Sosial dalam Pembelajaran IPS. Jurnal Harmony, 2 (1), 7-12

Sanjaya. (2013a). Penelitian Pendidikan Jenis Metode dan Prosedur. Jakarta: Prenada Media Group.

(2013b). Strategi Pembelajaran Berorientasi Standar Pendidikan. Jakarta: Kencana Prenadamedia Group.

Sapriya. (2014). Pendidikan IPS Konsep dan Pembelajaran. Bandung: PT Remaja Rodakarya.

Susanto, A. (2014). Pengembangan Pembelajaran IPS di Sekolah Dasar. Jakarta: Prenada Media Group.

Sutikno, S. (2014). Metode dan Model-Model Pembelajaran. Lombok: Holistica.

The Ministry Education. Bulding Conceptual Understandings of Social Science. New horizons for New Zealand Social Studies, 8 (330), 6.

Undang-Undang Republik Indonesia Nomor 20 Tahun 2003 tentang Sistem Pendidikan Nasional.

Widiantara dkk. (2013). Determinasi Penerapan Model Pembelajaran Inkuiri Sosial terhadap Sikap Sosial dan Hasil Belajar IPS Siswa Kelas VIII SMP Negeri 3 Singaraja. e-Journal Program Pascasarjana Universitas Pendidikan Ganesha, 3, 4 